\title{
On the depolarization of the electrodes by the solutions
}

\section{Lippmann}

To cite this article: M. Lippmann (1878) On the depolarization of the electrodes by the solutions, Philosophical Magazine Series 5, 6:35, 159-160, DOI: 10.1080/14786447808639492

To link to this article: http://dx.doi.org/10.1080/14786447808639492

曲 Published online: 13 May 2009.

Submit your article to this journal ๘

Џ Article views: 2

Q View related articles ¿ 
termined, according to the above formula, from the friction-constant, to be $4 \cdot 7$.

By multiplying the proportional numbers $\frac{v_{1}}{v_{2}}$ by $4 \cdot 7$, the values of $v$ in the penultimate column are obtained, which agree with the numbers in the last column, calculated by Kopp, as well as can in general be expected in experiments of this sort.

The molecular volume of free hydrogen, $4 \cdot 7$, is less by more than half than 11.0 , the value calculated from its liquid compounds. The author endeavours to account for this in the following manner. If molecules are spheres surrounded with envelopes of xther of variable density, two such molecules, on central impact taling place, will probably act on each other as soon as they arrive at a distance from one another equal to the sum of the radii of the actual sphere of action. The action lasts until the vis viva is reduced to zero and reversed. Molecules with greater velocities, in the gaseous state, will approach nearer to one another, and reciprocally penetrate with their rether envelopes more deeply than molecules with lower velocities, in the liquid state. Hence in the former case the radius of the apparent sphere of action, consequently the molecular volume, must be sinaller than in the latter.

To the same assumption of a variable sphere of action we are conducted, as first remarked by Director stefan, by the fact that the friction-constant is proportional not to the square root of the absolute temperature, but to another power of the same, which, according to the experiments of $A$. v. Obermeyer and the author, is greater than $\frac{1}{2}$ and at the highest is $=1$.

A second basis of explanation may, according to the view of Lothar Meyer, lie in the circumstance that, in determining the molecular volume from the density of the liquid compounds, with them the empty space is measured which is open to the atoms for their motions, while, from the magnitude of the obstruction which one particle coustitutes for another, only the volume of the gas particles themselves is determined.

Experiments with air under very low pressures led to this result - that while the pressure diminished from 754 to 0.03 millim. the friction-coustant became less by only about one half of its initial value, from which it may be seen how proportionally great must be the quantity of gas which remains in a very good vaeuum, since it can convey quantities of motion so considerable. This is in excellent accordance with the kinetic theory of gases, according to which, in a cubic centinetre of air of one millionth of an atmosphere pressure, nineteen billion molecules are still present. - Kaiserliche Akademie der Wissenschaften in Wien, math.-naturu. Classe, July 1, 1878.

\section{ON THE DEPOLARIZATION OF THE ELECTRONES BY THE SOLT- TIONS. BY M. LIPPMANN.}

It has long been known that certain salts possess a depolarizing property. The first pile with a constant current, constructed in 
1829 by M. Becquerel, owes its constancy to the employment of sulphate of copper; the sulphates of zine and cadmium have been made use of by MM. du Bois-Reymond and J. Regnault for the construction of impolarizable electrodes and constant elements. Notwithstanding the importance of its applications, this property appears to have been but little studied. The experiments I am about to describe have made evident an essential condition of the phenomenon.

It is the following: in order that the electrode may be depolarized, it must be formed of the same metal as is contained in the solution. Thus copper is the only metal which becomes depolarized in sulphate of copper, while gold, silver, and platinum are,polarized in that solution. Inversely, copper polarizes in sulphate of zinc, cobalt, \&c. A salt depolarizes only its own metal. To make the experiment, operating for example on sulphate of copper and platinum, two strips of platinum are to be immersed in the liquid, and put into communication with the poles of a capillary electrometer. The mercury column is then at zero. A feeble current is then cansed to pass into the liquid so as to employ one of the strips as negative or exit electrode. The electrometer shows a deflection, which remains even after the interruption of the current, thus proving that polarization is produced in the sulphate of copper, as it might have been produced in pure or acidulated water. For the same reason, a couple formed of strips of copper and platinum dipping in sulphate of copper furnishes only a current of brief duration, the platinum receiving, owing to its polarization, an electromotive force equal and opposite to that of the copper. One may even go further and communicate to the platinum, by means of an exterior pile, an electromotive force superior to that of the copper, so that then the platinum will behave like a more negative, more oxidizable metal than copper.

Similar experiments have been made with strips and solutions of silver, mercury, lead, cobalt, and zinc.

An application readily presents itself. Since the property of depolarizing a metal belongs exclusively to its salts, it permits us to detect the presence of that metal in a solution. Taking copper as an example, if we dip into the liquid to be tested a copper wire which we use for the negative electrode of a feeble current, it will be polarized if there is no dissolved copper, it will not be polarized if the solution contains $\frac{1}{5000}$ of sulphate of copper. It is possible, therefore, thus to detect the presence of copper in a mixture of metallic salts. With a silver wire we can in the same way test for silver. The delicacy of this electric process appears to be still greater for silver than for copper; but it has not yet been measured.-Comptes Rendus de l'Académie des Sciences, June 24, 1878, tome lxxxvi. pp. $1540,1541$. 